\title{
Analysis of International Mobile Roaming Services using Smart Call Assistant System in GSM Originating Call
}

\author{
Mareta Elisabeth $^{1}$, Pande Ketut Sudiarta ${ }^{2}$, I.G.A.K Diafari Djuni Hartawan ${ }^{3}$ \\ 1,2,3 Department of Electrical Engineering, Faculty of Engineering, \\ Udayana University, Bali - Indonesia \\ 1maretaelisabet@gmail.com
}

\begin{abstract}
This paper study the comparison Key Performance Indicator (KPI) of International Roaming in GSM Systems with or without Smart Call Assistant (SCA) system. SCA performs to correcting and call checking, when the customers dial the destination number (B \# number) but fail to call forwarded SCA significantly facilitate customers to make calls that are automatically corrects the error format calls made by customers of inbound roaming because the new code in the network that you visit (the visited network). From the data it can be seen that Call Success Rate (CSSR) percentage using SCA system higher than not using SCA systems. Thus, for the Call Drop Rate (CDR) using systems lower than not using SCA systems. This was because SCA system succeed to correcting and checking the error call.
\end{abstract}

Index Terms- international roaming, Key Performance Indicator (KPI), Call Success Rate (CSSR), Call Drop Rate (CDR), Smart Call Assistant (SCA).

\section{INTRODUCTION}

International Mobile Roaming (IMR) is a service that allows customers to seamlessly continue to use their mobile phone or other mobile device, to make and receive voice calls and text messages, browse the internet and receive emails, whilst visiting another country. [1]

Due to the international dialing format (international dialing codes) are different for each country, and sometimes even inbound roaming customers often make mistakes in using international dialing format when using the MOC services so the call does not connect to the destination number, which resulted in the inbound roaming customer satisfaction decreases. For inbound roaming customers can use the service without having to pay attention to the format of the MOC international calls are correct, then use the SCA system (Smart Call Assistant) as the supporting system.[2]

Smart Call Assistant (SCA) is a system for correcting the call and call checking, where when customers dial the destination number (B \# number) but fail to call forwarded SCA significantly facilitate customers to make calls that are automatically corrects the error format calls made by customers of inbound roaming because the new code in the network that you visit (the visited network). [3]

In this research, it takes a trace log data with test directly using the Polystar tools and Traffic News to know the comparison operator Telkomsel network calls with and without SCA SCA Performance, and data obtained from
Roamware SCA tools which will then be processed and analyzed to find out the quality of service the influence of SCA implementation calls the overall international operators in the three countries with the highest incoming data so that next could be a parameter in the repair services provided.

\section{MethodS AND PROCEDURES}

Investigation method for Analysis of International Mobile Roaming Services using Smart Call Assistant System in GSM Originating Call is done with the following steps.

The initial stage is doing a trace $\log$ (trial international calls directly) with Traffic News and Polystar Tools. For signalling comparison in this study used 2 operator of Malaysia, U Mobile which already implemented system SCA and Maxis are not implemented system SCA. The data captured is the Insert Subscriber Data, signalling, DxCause on each operator to be aware of the comparison of the operator U Mobile (already implemented SCA) and operator Maxis (not yet implemented SCA). After that is done the analysis to find out the difference a call by the foreign operator Telkomsel network already implemented system SCA and which are not.

The next stage took the report contains data Performance SCA operator Telkomsel's network abroad in an already implemented Smart Call Assistant (SCA) from all over the Country, further classify data based on analysis lifted using a PivotTable. Then do an analysis of how big the number of international calls which are in network Telkomsel, against the level of success and failure of the foreign operators that 
are in the network already implemented Telkomsel and Smart System Call Assistant (SCA) by calculating the degree of success and failure of calls, analyzing the influence the system SCA against international calls, analyzing the causes of the failure of the call. After the analysis is performed, then give advice or solutions to overcome the failure of international roaming calls are already implemented system Smart Call Assistant.

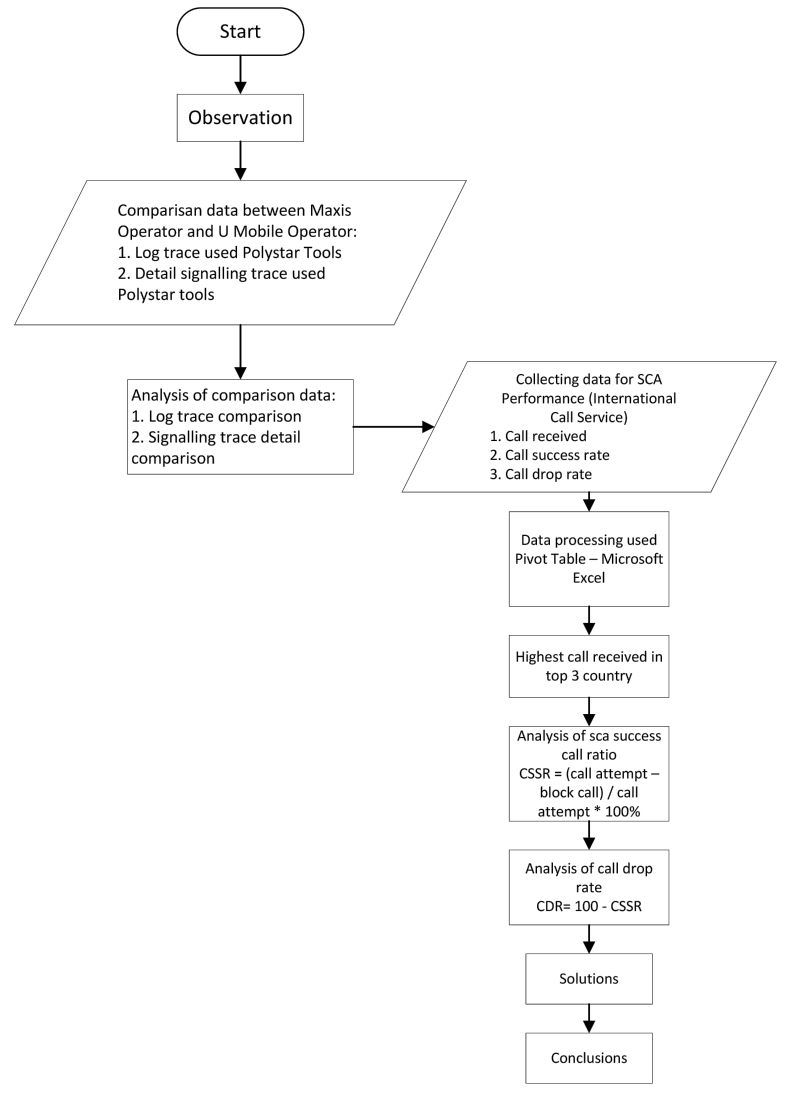

a. Calling scenario (incoming call):

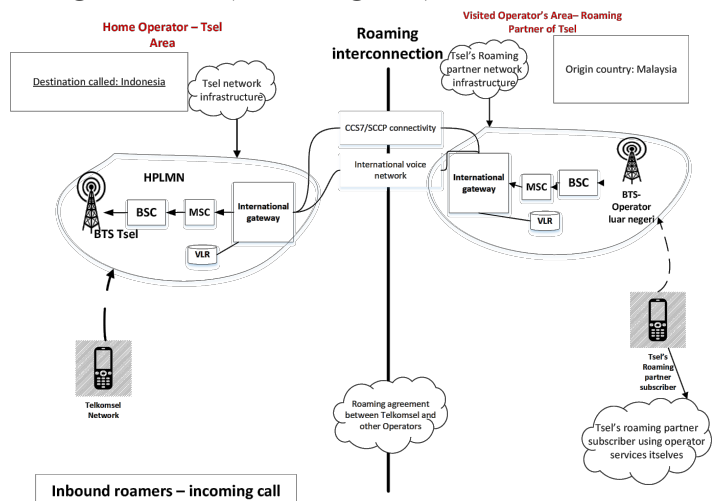

Fig. 1. Incoming Call Scenario

In Figure 1 describes a general description of the process of incoming calls (incoming call inbound roamers) from overseas operators who wish to call Indonesia. Overseas operator customers who already have a roaming agreement between a home network overseas operator and a visited network Telkomsel network, calls can occur and the device is allowed to access all international roaming services agreed by both operators.

Customers of overseas operators are dialing Indonesian numbers. When customers make calls in their home countries, the network infrastructure used is owned by operators in the country, then it will be connected to an international gateway that connects country A to the operator network infrastructure in Indonesia. If there is no error when making a call, then the call transaction will be successful, if something goes wrong, it will be evaluated as the cause of the call failure can occur.

In international roaming services, the most common error is found when customers are assigned a country code destination telephone number, so the Smart Call Assistant (SCA) system that functions as a Signalling Control Point (SCP) will improve incorrect country code. Although roaming agreements have been established on both operators, there are operators who have implemented the SCA system with those who do not. Discussion between operators who implemented the system and those that will not be discussed in the next sub-chapter.

b. Signalling Result Between Operator With or Without SCA System

-U Mobile (Implemented by SCA system)

TABLE I

Signalling result for U Mobile Operator

\begin{tabular}{|c|l|l|c|}
\hline \multirow{2}{*}{ Operator } & \multicolumn{3}{|c|}{ Insert Subscriber Data (ISD) } \\
\cline { 2 - 5 } & \multicolumn{1}{|c|}{ SCCP GT Calling } & \multicolumn{1}{|c|}{ SCCP GT Called } & Status \\
\hline \multirow{4}{*}{$\begin{array}{l}\text { U Mobile with } \\
\text { SCA system }\end{array}$} & 601214080020 & $628210 \mathrm{xx}$ & End \\
\cline { 2 - 5 } & 62821090190 & 6281107004 & End \\
\cline { 2 - 5 } & 62810181009190 & 6281106067 & End \\
\cline { 2 - 5 } & 6281107038 & 081107132 & Timeout \\
\hline
\end{tabular}

-Maxis (Without SCA system)

TABLE II

Signalling result for Maxis Operator

\begin{tabular}{|c|l|l|c|}
\hline \multirow{4}{*}{$\begin{array}{c}\text { Operator } \\
\text { Maxis } \\
\text { Without } \\
\text { SCA }\end{array}$} & \multicolumn{1}{|c|}{ Insert Subscriber Data (ISD) } \\
\cline { 2 - 5 } & 601200014082 & 628110723127 & End \\
\cline { 2 - 5 } & 601200014082 & 628110723149 & End \\
\cline { 2 - 5 } & 601200014082 & 628110723142 & End \\
\cline { 2 - 5 } & 601215353275021 & 08110723127 & Time out \\
\hline
\end{tabular}

c. Detail Signalling Log Trace Result Between Operator With or Without SCA System

-Maxis (Without SCA system)

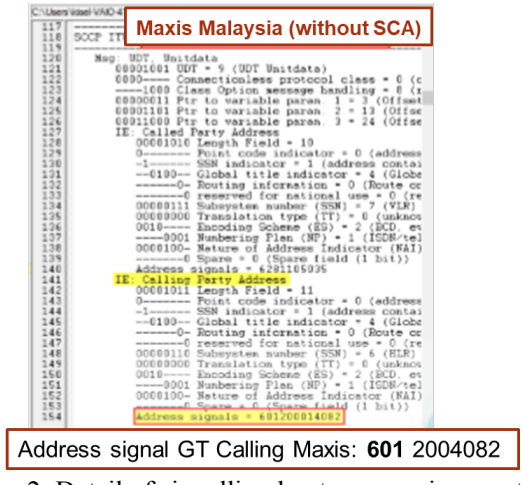

Fig. 2. Detail of signalling log trace maxis operator 


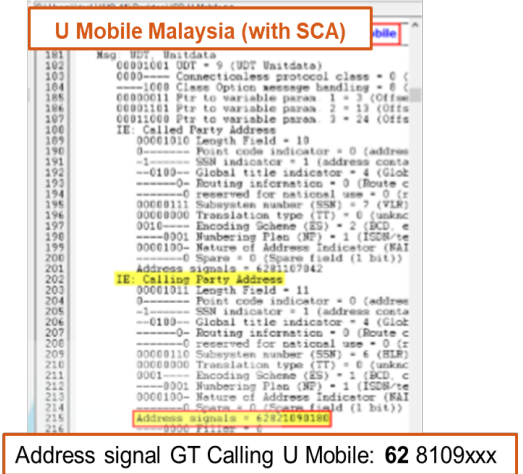

Fig. 3. Detail of signalling log trace U Mobile Operator

Based on Fig 2. And Fig 3, there are differences in the signalling trace of Maxis and U Mobile operators, namely in the address signals which contain information on SCCP GT Calling. Where for GT Calling Maxis customers are 601 20001xx, while for GT Calling U Mobile customers are 62 $8109 x x$. Normally for a reply from this ISD process is a reply from the GT HLR located at the HPLMN with the GT Calling or GT HLR number, but on this SCA system the GT Calling obtained is replaced by the GT SCP SCA which sends the VLR CAMEL Subscription Info (CSI) to the number inbound roaming customers. CAMEL Subscription Info (CSI) is customer profile information so that it can provide services in accordance with customer profiles. CSI will be requested by MSC / VLR when the customer performs a location update.

\section{d. SCA Performance Result For Call Setup Success Rate} CALL RECEIVED DECEMBER 2017- MEI 2018

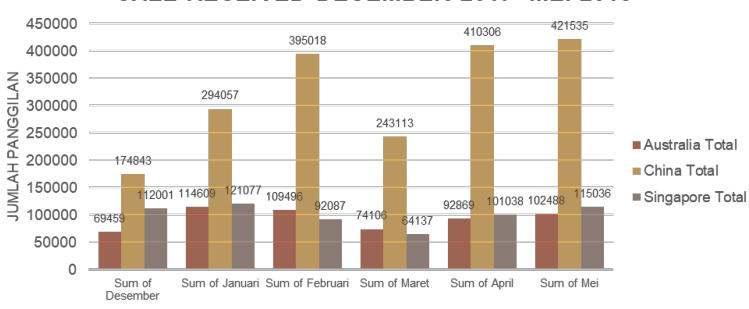

Fig. 4. Call Received for International Calls Dec 2017 - May 2018

Based on Fig. 4 can be seen that countries with the highest call received / incoming calls in Telkomsel networks are Australia, China and Singapore. From this basis to analyze the effect of the SCA system on the success and failure of roaming international calls, it will be reduced to interconnection in these 3 (three) countries and shown below:

-Call Setup Success Rate for Operators in China:

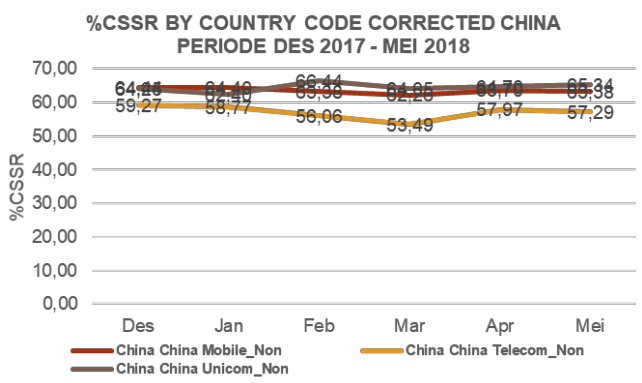

Fig. 5. Call Setup Success Rate Before SCA Correction on China

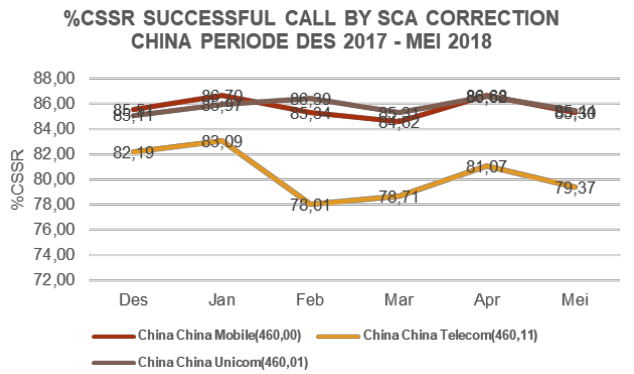

Fig. 6. Call Setup Success Rate After SCA Correction on China

- Call Setup Success Rate for Operators in Australia:

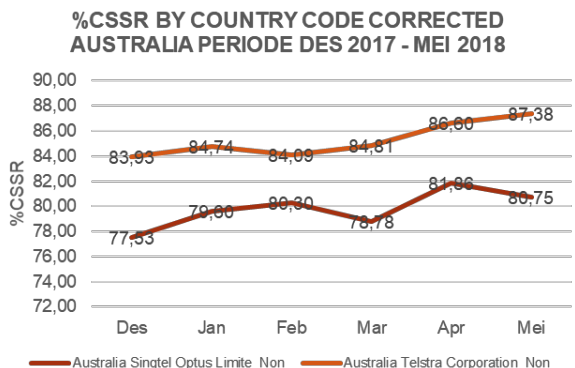

Fig. 7. Call Setup Success Rate Before SCA Correction on Australia

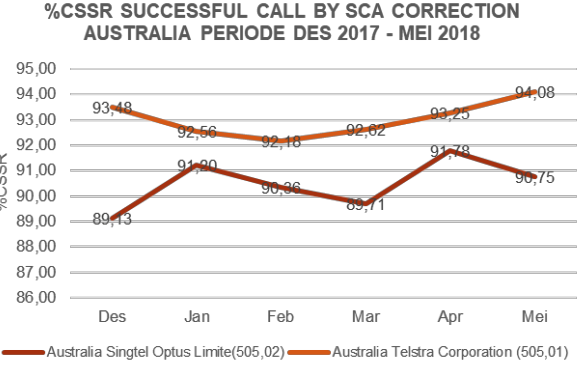

Fig. 8. Call Setup Success Rate After SCA Correction on Australia

- Call Setup Success Rate for Operators in Singapore:

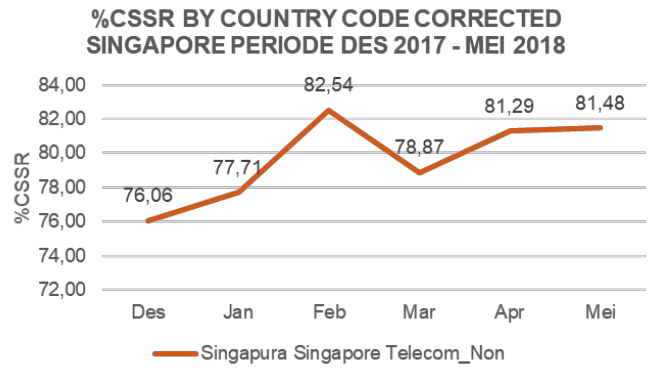

Fig. 9. Call Setup Success Rate Before SCA Correction on Singapore

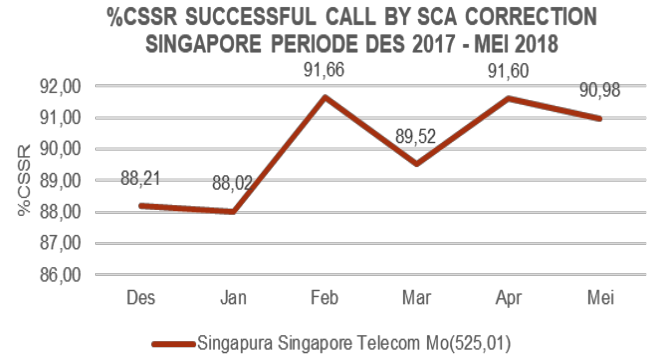

Fig. 10. Call Setup Success Rate After SCA Correction on Singapore 
Referring Fig. 5., Fig. 6., Fig 7., Fig. 8., Fig 9., and Fig. 10., it shown the percentage of operator Call Setup Success Rate (CSSR) implemented by the SCA system. Australia with Singtel Optus Limite, China with China Mobile and Singapore with Singapore Telecom with different success rates.

Referring to performance licensed by PT. Telkomsel with before being corrected by the SCA system CSSR performance can be categorized in a bad condition, for example for Singapore. In Singapore with Singapore Telecom operators, the CSSR obtained before the SCA system in May was $81.48 \%$, while after being repaired by the SCA CSSR system it was obtained at $90.98 \%$.

So it can be concluded as a whole in 3 countries, SCA succeeded in carrying out its function to improve CSSR for operators that implemented SCA in the normal - good state accordance with KPI standard set by Telkomsel, while for non-implementation the SCA system was obtained in less categories and did not comply KPI determined by Telkomsel.

\section{e. SCA Performance Result For Call Drop Rate}

\section{-Call Drop Rate for Operators in China:}

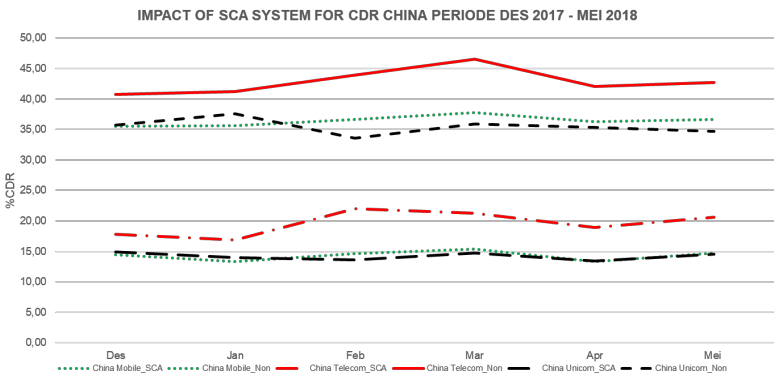

Fig. 11. Result of Call Drop Rate in China

-Call Drop Rate for Operators in Australia

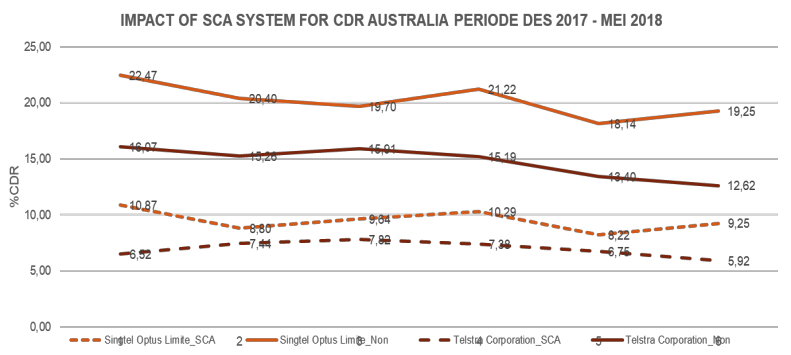

Fig. 12. Result of Call Drop Rate in Australia

-Call Drop Rate for Operators in Singapore IMPACT OF SCA SYSTEM FOR CDR SINGAPORE PERIODE DEC 2017 - MEI 2018

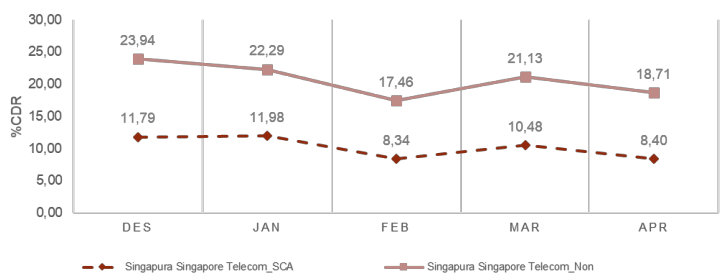

Fig. 13. Result of Call Drop Rate in Singapore

Fig. 11., Fig. 12., and Fig. 13., are shown us the percentage of Call Drop Rate (CDR) operators implemented by the SCA system. Australia with Singtel Optus Limite, China with China Mobile and Singapore with Singapore Telecom with different success rates.

Referring to KPI standard determined by PT. Telkomsel before the existence of the SCA system can be categorized in bad conditions, for example for Singapore. In Singapore with Singapore Telecom operators, the CDR obtained before the SCA system in May was $18.52 \%$, while after being repaired by the SCA CDR system it was $9.02 \%$. Of the total transactions, the disruption that occurs is mostly caused by problems that are common in the field of cellular telecommunications, namely the number of service users is greater than the channel that has been provided by the operator, so that it needs to be sent back from where the failure began to the destination.

Of the total transactions, the disruption that occurs is mostly caused by problems that are common in the field of cellular telecommunications, namely the number of service users is greater than the channel that has been provided by the operator, so that it needs to be sent back from where the failure began to the destination. Example for operators in China, has the largest number of calls compared to Australia and Singapore. That is why China has a greater percentage of failure than Australia and Singapore which can be seen in terms of the number of channels, but in this thesis the author does not have the data on the number of channels provided so that this thesis can be analyzed further to analyze the factors causing failure of international calls by looking the number of channels provided and see the failure factor on the A interface (radio). When viewed from the causes of failure, the SCA system can be identified as two, namely because of subscriber behavior and system failure when translating / correcting calls (SCA Translation Fail).

It can be concluded as a whole in 3 countries, operators with SCA systems get\% CDR under normal conditions - both meeting the CDR KPI expected by operators per month, whereas for those not implemented the SCA system $\%$ CDRs obtained in the category are lacking and do not meet KPI standard determined by Telkomsel, it is necessary to further analyze the causes of failures that occur in overseas operators in Telkomsel networks without the SCA system on the A interface (radio).

\section{CONCLUSIONS}

Based on the results of the analysis and testing of the system then it can be taken a few conclusions as follows:

1. There is a difference between operators using the SCA system and not in the signalling process, including the Insert Subscriber Data (ISD) transaction process, the GT Calling parameter will change to GT SCP SCA which functions to send VLR CAMEL Subscription Info (CSI) to the inbound roaming customer number.

2. Percentage of Call Setup Succesful Rate in 3 countries, Australia, China, and Singapore in average before 
implemented by SCA system was $81,48 \%$, while after being corrected by SCA system became $90,98 \%$, which after repaired by SCA system complied with KPI standard applied by PT. Telkomsel is normal-good state.

3. Percentage of Call Drop Succesful Rate in 3 countries, Australia, China, and Singapore in average before implemented by SCA system was $18,52 \%$, while after being corrected by SCA system became $9,02 \%$, which after repaired by SCA system complied with KPI standard applied by PT. Telkomsel is normal-good state.

\section{REFERENCES}

[1] Mauro, I., \& Raval, V. (2012). International Roaming Explained. London: GSMA Head Office.

[2] Moshirian, S. (2015). Performance of International Roaming Location Update in $3 \mathrm{G}$ and $4 \mathrm{G}$ Networks.

[3] Mobileum. (2012). SCA User Guide. USA 